\title{
Credibility of Radio Programmes in the Dissemination of Agricultural Information: A Case Study of Air Dharwad, Karnataka
}

\author{
Onkargouda Kakade \\ Associate Professor and Chairman, Department of Journalism and Mass Communication, Karnataka State \\ Women's University, Toravi campus, Bijapur 586109. (Karnataka, India)
}

\begin{abstract}
Communication channels play pivotal role in disseminating information. But when the bulk of population is illiterate and inaccessible to modern means of communication, the challenge is all the more difficult. In this situation mass media like radio can play a significant role in disseminating information. Radio is a very popular and powerful communication medium and has proved very effective in helping to disseminate agricultural information. One of the special features of All India Radio is its 'farm and home units', which are engaged in disseminating scientific information about farming to needy people living mostly in poorly accessible villages. There are number of sources of agricultural information which a farmer can use. In order to find out how the farmers rate radio broadcast in respect of the credibility of the information as compared to other sources. The radio programme of AIR Dharwad has been taken to investigate the credibility issue. The respondents for this study were selected from three districts of Karnataka. From Dharwad-88 farmers; Gadag86 farmers and Bijapur-86 farmers were selected randomly. Finally 260 farmers were selected for the study. The primary data was collected through structured questionnaire. The results indicate that the farm radio programmes are the second credible, next to agriculture extension workers. This might be due to the fact that extension worker is very much available in the village and gives the information in required format. It is obvious that the Farm and Home units programmes should be more effective, to achieve high credibility. Further, content of the farm radio programmes, which once broadcasted should be made available in print form and possibly in audio form as well in all the Raita Salaha Kendras (Advice Centre for Farmers) for reference by the farmers.
\end{abstract}

Key words: Credibility, Radio, Agriculture information

\section{Introduction:}

India is the second largest producer of agricultural products and it also has second largest arable land. India occupies top global position in the production of milk and pulses and the second position in the production of rice, wheat, cereal grains, sugarcane, fruits and vegetables, tea, egg and culture fishery. The agriculture sector is the backbone of Indian economy.

The success of agricultural development programmes in developing countries largely depends on the nature and extent of use of mass media in mobilization of people for development. The planners in developing countries realize that the development of agriculture could be hastened with the effective use of mass media (Purushothaman C. 2003)

Radio is considered as an effective tool to disseminate agricultural information among the farmers and it is the most powerful mass media for broadcasting Information quickly. It is a powerful communication medium, particularly in India where, in the absence of regular and stable electric supply in rural areas. People have to depend on radio to meet their needs of information.

Radio can reach large audience at the same time. In terms of cost, it is an extremely economical medium as compared to other extension media and methods involving individual and group contacts. Radio is considered as a credible source of information and is taken as authentic, trustworthy and prestigious medium of communication". Credibility refers to the trustworthiness of information perceived by farmers as important and gave weightage in adoption of information. This influenced the adoption of agricultural technology as farmers think them as praiseworthy. A credible source of information stimulates farmers to adopt the recommended package which is suitable to local farm condition.

One of the special features of All India Radio is its 'farm and home units', which are engaged in disseminating scientific information about farming to needy people living mostly in poorly accessible villages. There are number of sources of agricultural information which a farmer can use. In order to find out how the farmers rate radio broadcast in respect of the credibility of the information as compared to other sources. The radio programme of AIR Bijapur has been taken to investigate the credibility issue. 


\section{Review of literature:}

Roy et al (1968) studied agricultural innovation among Indian farmers and found that out of four muchused sources radio was given fourth, that is the last place for its credibility. Demonstration, neighbor and village level worker were accorded first second and third place, respectively.

Sandhu (1970) reported that in terms of the credibility placed upon radio as sources of farm information, radio was ranked third amongst seven selected sources. The first two positions went to demonstrations and university scientists respectively.

Ambasthe (1974) in his study at Delhi found that radio was at the top as for as its credibility is concerned as a source of farm information. According to Somasundaram (1976) radio was first in order of channels utilized by both adopters and non- adopters for getting information about all the practices. Hiriyannaiah (1977) found that out of seven sources of information, radio has received second rank in credibility by the graduate and educated farmers of Dharwad district.

Annamalai (1979) also reported that the awareness stage radio was utilized as farm information sources for the practices like seeds treatment and fertilizers application. Patil (1980) in a study conducted in Bijapur district has brought to light that amongst ten sources of information, small farmers has accorded fifth rank to radio compared to other farmers who have accorded second rank.

Joshi (1985) found radio as the effective source credibility utilized by the farmers in sixth position. According to Chandra mouli (1990) radio was first in order of channels utilized by farmers for getting information about all the practices.

Tamuli et al (1999) reported that in progressive village the dairy farmers perceived that veterinary assistant surgeon was unequivocally ranked top as far as credibility of information source in concerned and trustworthy, similarly radio and television are ranked second and third as credible and trust worthy source of information as perceived by farmers.

Nazam (2000) found that $68.8 \%$ of the respondents became aware of modern technology through radio/TV while extension worker, newspaper and agricultural magazines served as sources of information for $23.3,13.3$ and $3.3 \%$ of respondents respectively. The possible reason for the difference may be time factor; the gap between two studies is more than twenty years. Thus with the passage of time situation might have changed. The difference may also be due to the nature of respondents; in the present case all the respondents were literate.

Opera (2008) found that $88.10 \%$ of the farmers regarded the extension agents as their source of information, followed by the fellow farmers, radio, and television as indicated by $71.20,63.20$, and $43.30 \%$ of the farmers, respectively. The majority $(70.00 \%)$ of the farmers preferred the extension agents over the other sources (including radio, friends \& relatives, and television).

\section{Statement of the problem:}

Radio is one of the most powerful mass media for the dissemination of agricultural information and its effectiveness has been well established by many researchers. Credibility refers to the degree of trust-worthiness and expertness accorded to a source of Information by his audience at a given time. Credibility of a source is not fixed; it is flexible, with the change of time and place. Therefore, it was felt necessary to have an in-depth research study on the "Credibility of Radio Programmes in the Dissemination of Agricultural Information: A Case Study of AIR Dharwad, Karnataka". Hence, the present investigation was carried out with the following objectives:

\section{Objectives:}

- To assess extent of utilization of information through radio agriculture programmes.

- To examine the type of presentation preferred by the farmers.

- To find out the credibility of radio as a source of information.

\section{Research Methodology:}

For the present research, a multi-stage sampling technique was used. First stage of sampling consisted of selection of district, at the second stage Taluks (Blocks) were selected and in the third stage, villages were selected. At the final stage respondents were chosen.

The respondents for this study were selected from three districts of Karnataka. From Dharwad-88 farmers; Gadag-86 farmers and Bijapur- 86 farmers were selected randomly. Finally 260 farmers were selected for the study. The primary data was collected through structured questionnaire. 
Findings and discussions:

Table- 1: General characteristics of the farmers

\begin{tabular}{|l|l|r|}
\hline Characteristics & Number & Percentage \\
\hline Gender & & \\
\hline Male & 173 & $66.54 \%$ \\
\hline Female & 87 & $33.46 \%$ \\
\hline Age & & \\
\hline Below 20 years & 86 & $33.08 \%$ \\
\hline $21-30$ years & 126 & $48.46 \%$ \\
\hline $31-40$ years & 30 & $11.54 \%$ \\
\hline 40 years and above & 18 & $6.92 \%$ \\
\hline Education & & $1.15 \%$ \\
\hline Illiterate & 3 & $14.23 \%$ \\
\hline Primary school & 37 & $46.15 \%$ \\
\hline High school & 120 & $35.39 \%$ \\
\hline College & 92 & $3.08 \%$ \\
\hline Post- Graduation & 8 & \\
\hline
\end{tabular}

The data reported in Table 1 indicated that majority of the respondents $(66.54 \%)$ were male and rest were female $(33.46 \%)$. Further, the data indicated that about half of the respondents $(48.46 \%)$ were in the age group of 21-30 years. While $33.08 \%$ of the respondents were below 20 years, about $11.54 \%$ were in the age group of 31-41 years and only $6.92 \%$ were above 41 years age group.

Education-wise break up of respondents, presented in the above table found that $46.15 \%$ of the respondent have completed high school studies followed by graduates $(35.39 \%)$ and $14.24 \%$ who completed primary school education. About $3.08 \%$ were post graduates. It is interesting to note that there were 3 farmers $(1.15 \%)$ who were illiterates, but listen to the Farm Radio programme regularly.

Table-2: Source credibility on farm information among respondents.

\begin{tabular}{|l|l|l|}
\hline Source of information & Score & Rank order \\
\hline Agriculture demonstrator & 765 & I \\
\hline Radio & 720 & II \\
\hline Neighbor & 489 & III \\
\hline University scientist & 446 & IV \\
\hline T.V & 413 & V \\
\hline Newspaper & 358 & VI \\
\hline Farm magazine & 348 & VII \\
\hline
\end{tabular}

There are number of sources of agricultural information which a farmer can use. In ordered to find out how the farmers rate the radio broadcast in respect of the credibility of the message as compared to other sources, the respondents were requested to indicate their rank order of seven possible sources of information.

Table 2 deals with the expressed opinion of registered respondents about the credibility of agriculture programmes. The data revealed that radio was the second most credible source ranked by the registered farmers after sericulture demonstrator, followed by T.V, newspaper, and farm magazine for information regarding to sericulture. It is interesting to note that radio was given second preference for agriculture information. It is further interesting to note that the difference between the total score obtained for radio and the next ranked source neighbors is very wide. All other sources like University scientist, T.V, Newspaper and Farm magazines are thus raked below. Such high credibility is indicative of the confidence the farmers have in the agriculture programmes, as almost a companion like agriculture demonstrator who spends quiet a lot of time with farmers being his study. The first rank was given to the agriculture demonstrator as source credibility of information regarding agriculture.

Table-3: Types of presentation preferred by respondents.

\begin{tabular}{|l|l|l|}
\hline Types of presentation & Score & Nank order \\
\hline Discussion & 797 & I \\
\hline Dialogue & 747 & II \\
\hline Question-Answer & 527 & III \\
\hline Straight talk & 526 & IV \\
\hline
\end{tabular}

A critical observation of the table 3 reveals that discussion, dialogue, question-answer and straight talks were the priority preferences in order of highest to the lowest. The results of this study revealed that the farmers ranked discussion presentation as the first choice, followed by dialogue; question-answer and straight talk was ranked as the least preferred type of presentation. 
The possible reason for the above findings might be that in the discussion method, the local experiences with innovation will be discussed. Also there would be detailed analysis of pros and cons of the technology adoption touching all other areas related to technology promotion. These factors might have influenced the farmers to assign first rank to discussion type of presentation. The least preference to the straight talk type of presentation might be its limitation to cover wide range of the topic, lack of local specificity and the style of deliver of talk may be monotonous.

Table- 4: Extent of utilization of information gained through the agriculture programmes

\begin{tabular}{|l|l|r|}
\multicolumn{2}{c}{ Nor } \\
\hline Information used & Number & percentage \\
\hline Fully & 142 & $54.62 \%$ \\
\hline Partially & 83 & $31.92 \%$ \\
\hline Not at all & 35 & $13.46 \%$ \\
\hline Total & 260 & $100 \%$ \\
\hline
\end{tabular}

A close observation of the table 4 reveals that more than half of the respondents $(54.62 \%)$ fully used information in their day today farming and $31.92 \%$ used partially and farmers who have not used the information were only $13.46 \%$.

Table- 5: Respondents' opinion regarding reliability of content of agriculture programmes

\begin{tabular}{|c|c|c|}
\hline & \multicolumn{2}{|c|}{$\mathrm{No}=260$} \\
\hline opinion & Number & percentage \\
\hline Fully reliable & 137 & $52.69 \%$ \\
\hline Some extent reliable & 102 & $39.23 \%$ \\
\hline Not at all & 21 & $8.08 \%$ \\
\hline Total & 260 & $100 \%$ \\
\hline
\end{tabular}

Table 5 indicates that more than half of the respondents $(52.69 \%)$ opined that the content of agriculture programmes was fully reliable, followed by some extent reliable $(39.23 \%)$. A very small percentage $(8.08 \%)$ expressed that the content was non reliable. A higher percentage of farmers considered the information broadcast through agriculture programmes as "fully reliable".

Table- 6: Respondents' opinion about language used in agriculture programmes

\begin{tabular}{|l|l|r|}
\hline \multicolumn{2}{|c|}{ No = 260 } \\
\hline Very easy to understand & Number & percentage \\
\hline Easy to understand & 166 & $63.85 \%$ \\
\hline Not easy to understand & 75 & $28.85 \%$ \\
\hline Total & 19 & $7.30 \%$ \\
\hline
\end{tabular}

The data presented in table 6 on opinion about language used in agriculture programmes. The opinion of the respondents was recorded on the three point continuum; very easy to understand, easy to understand and not easy to understand. About two third of respondents $(63.85 \%)$ recorded their opinion as very easy to understand, followed by easy to understand $(28.85 \%)$ and only $(7.30 \%)$ not easy to understand. The above finding shows that the language used in agriculture programmes was rated as "very easy to understand.

Table - 7: Farmers opinion about practicability of information presented through agriculture programmes

\begin{tabular}{|l|l|r|}
\multicolumn{2}{|c|}{ No $=260$} \\
\hline Opinion & Number & percentage \\
\hline Practicable & 140 & $53.85 \%$ \\
\hline Somewhat practicable & 93 & $35.77 \%$ \\
\hline Not practicable & 27 & $10.38 \%$ \\
\hline Total & 260 & $100 \%$ \\
\hline
\end{tabular}

Table 7 pertains to the opinion of farmers about the practicability of information presented through agriculture programmes. A majority of the farmers $(53.85 \%)$ opined that the information presented through agriculture programmes was "practicable" followed by somewhat practicable $(35.77 \%)$ and not practicable $(10.38 \%)$. It is, therefore, inferred that a highest percentage of farmers considered the information broadcast through agriculture programmes as "practicable". 


\section{Conclusion:}

The broadcasting stations of All India Radio are providing a variety of programmes in the areas of news, education, rural development, entertainment, commercial broadcasting service etc. The farm and home unit of All India Radio programmes viz., "Krishiranga" and "Hints to farmers". These programmes deal with several aspects of agricultural information. Radio is considered as an effective tool to disseminate agricultural information among the farmers and it is the most powerful mass media for broadcasting Information quickly. This study indicates that the agricultural programmes commanded a universal audience in terms of age. However, a great majority $(48.46 \%)$ of them belonged to below 30 years age group. The study clearly shows that most of the farmers (46.15\%) were belonged to high school education category. A great majority of the farmers listen agricultural programmes regularly. A majority of the farmers preferred discussion method of presentation. While straight talk mode of presentation was the least preferred by the farmers. The finding shows that radio was ranked second among the seven different sources of credibility regarding agricultural information by the farmers and agriculture demonstrator was ranked first. Majority of the farmers considered information broadcast through agricultural radio programmes as "reliable". A large percentage of farmers opined that the information broadcast through agricultural radio programmes as "practicable". A large percentage of farmers considered the style of presentation of programmes as "understandable".

\section{References:}

[1]. Ambastha C. K (1974) 'Communication Patterns in Farm Innovation Development, Extension and Client System, in Bihar: A system Approach

[2]. Annamalai (1979) 'A Study on Utilization of Farm Information Sources in the Adoption Process', M.Sc. Thesis, T.N.A.U, Coimbatore.

[3]. Anonymous (2012) Publication Malyalam Manorama,Kottayam (PP-670-675,658-659,487-488)

[4]. Chandramouli (1990) 'A Report on Sasya Sanjeevini Serial Programme, All India Radio Bangalore.

[5]. Hiriyannaiah Y.T (1977) 'A comparative study of adoption behavior, communication pattern and value orientation of the graduate, non-graduate and illiterate farmers of Malaprabha command area of Dharwad district, Karnataka State. M.Sc (Agri.) thesis (Unpubl) UAS, Bangalore.

[6]. Joshi C.D (1985) 'Evaluative study of the effectiveness of nabhovani sheti shala (Farm - School - on AIR) in the transfer of technology to the farmers with special reference to poultry keeping Acc No. 1557. M.Sc (Agri).

[7]. Meena B.S (2010) 'Communication Sources Credibility and Utilization Pattern among Farmers', Raj. J. Extn. Edu. 17 \& $18: 40$-43.

[8]. Nazam, M. 2000. A sociological study of the factors affecting the adoption rate of modern technologies in tehsil Chistian. M. Sc. Thesis, Dept. of Rural Soc., Univ. of Agri., Faisalabad.

[9]. Opera, N. U. 2008. Agricultural information sources used by farmers in Imo state, Nigeria. Info. Dev., 24(4): 289-295.

[10]. Patil L.H (1980) 'The impact of radio lessons on knowledge and adoption behavior of ground nut cultivators of Dharwad district, Karnataka State. M.Sc (Agri.) thesis (Unpubl) UAS, Bangalore.

[11]. Proggya Ghatak (n.d) 'Development of Mass Media and its Extension in Agriculture: A Feedback Review oAudience Research Survey in AIR, Murshidabad, West Bengal' JRF-UGC, Dept of Anthropology, University of Calcutta, West Bengal, India.

[12]. Purushothaman $C$ et al (2003) 'Role of mass media in agriculture'Global Communication Research Association Center for International Communication, MaCquarie University, Sydney, Australia GCRA-Varanasi Conference.

[13]. Roy P., Waisanon F.R, and Rogers E.M (1968) 'The impact of communication on rural development - An investigation in Costarica and India, UNESCO, Paris.

[14]. Sandhu A.S (1970) 'Characteristics, listening behavior and programme preference of the radio owning farmers in Punjab, Ph.D Thesis, PAV, Ludhiana.

[15]. Somaasundaram D. (1976) 'A diagnostic study of small farmers with respect to new agricultural technology and its effective communication for adoption, Ph.D Thesis, A.I.R.A, New Delhi.

[16]. Tamuli U.R, Kakaty H.N and Borgohain A. (1999) 'Credibility of Different Information Source Utilized By Dairy Farmers of Progressive and Non-Progressive Villages. Maharashtra. J.Ext.Edn. 18:143-145. Tirupti, district, Chittoor, India. 